\title{
Morphological and functional diversity of minor ampullate glands in spiders from the superfamily Amaurobioidea (Entelegynae: RTA clade)
}

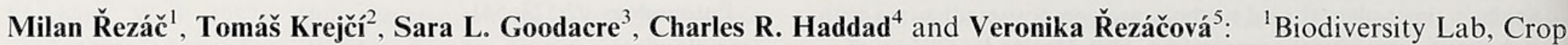 \\ Research Institute, Drnovská 507, CZ-16106 Prague 6-Ruzyně, Czechia, E-mail: rezac@vurv.cz; ${ }^{2}$ Faculty of \\ Environmental Sciences, Czech University of Life Sciences Prague, Kamýcká 129, CZ-16521 Prague 6 - Suchdol, \\ Czechia; ${ }^{3}$ School of Life Sciences University of Nottingham, Nottingham, NG7 2RD, United Kingdom; ${ }^{4}$ Department of \\ Zoology \& Entomology, University of the Free State, P.O. Box 339, Bloemfontein, Free State 9300, South Africa; \\ ${ }^{5}$ Laboratory of Fungal Biology, Institute of Microbiology, Academy of Sciences of the Czech Republic, Vídeňská 1083, \\ CZ-14220 Prague 4 - Krč, Czechia
}

\begin{abstract}
Minor ampullate glands produce fibers that are involved in construction of the complex adhesive band for capturing prey, which is produced by particular cribellate spiders. Despite such a specific role, however, the glands persist even in species where production of cribellate capturing bands no longer occurs. In these species, minor ampullate fibers are instead used to reinforce major ampullate fibers in draglines and capturing webs. The fibers are also used in combination with the aciniform fibrils to make silk for bridging lines - airborne lines used by spiders to allow them to move to points on the substrate where these threads adhere. In this study, we compare the morphology of minor and major ampullate glands in related cribellate and ecribellate groups within spider families of the group traditionally termed the Amaurobioidea, which lies at the base of the RTA clade. We found that the minor ampullate glands are bifurcated in the cribeliate members of this group, in particular in the representatives of the families Amaurobiidae, Titanoecidae, Desidae, Amphinectidae and Phyxelididae. In ecribellate representatives, the major ampullate glands are never bifurcated. We found irregularly branched minor ampullate glands in some representatives of the family Agelenidae. In other ecribellates, the glands are either unbranched or they are absent. Thus, bifurcation of the minor ampullate gland seems to be important in determining some aspect of cribellate capturing band formation that is as yet undetermined.
\end{abstract}

Keywords: Cribellate capturing threads, major ampullate, silk glands, spinnerets

Spiders exhibit a great diversity of silk gland types (Kovoor \& Peters 1988). The glands produce silks with a range of different physical properties that are used for different functions. Most attention so far has been paid to the major ampullate glands and their silks. These glands are conspicuous in being the largest in size, and they produce long, thick fibers that are the toughest of all the silk fibers. Spiders use them for walking or dropping draglines, for constructing frames of webs, or as gossamer threads for ballooning (Foelix 2011). The major ampullate glands are usually the only large glands that open onto the anterior (anterior lateral) spinnerets of araneomorph spiders. The large glands that open onto the median (posterior median) spinnerets are called the minor ampullate glands because their morphology resembles that of the major ampullate glands but they are usually smaller in size.

In some cribellate spiders, minor ampullate glands produce fibers that form part of the complex adhesive band used for capturing prey. In this capturing band, a mass of adhesive fibrils produced by cribellar glands is supported by products from three other gland types. The product of the paracribellar glands probably fixes the cribellate fibrils to the fibers from the minor ampullate glands. These fibers also act as springs, tending to contract the whole band (Peters 1987). The last component of the cribellate capturing band is the pair of axial fibers produced by the pseudoflagelliform glands, which open onto the posterior lateral spinnerets. The pseudoflagelliform fibers are straight because they are not combed out using the calamistrum on the hind legs. This is in contrast to products from the previously mentioned glands that open onto the cribellum and the posterior median spinnerets. The pseudo- flagelliform glands are phylogenetically homologous to the flagelliform glands that produce the axial fibers of the sticky spiral of Araneoidea orb webs.

In contrast to the cribellar and paracribellar glands, which are always absent in ecribellate spiders, minor ampullate glands have not been lost in the majority of cases, even where species no longer produce the cribellate capturing band. Instead, the products of the minor ampullate gland have diversified to fulfil other functions. In spiders from the group Araneoidea, they reinforce the major ampullate fibers in draglines or in construction elements of the webs (Work 1981; Peters \& Kovoor 1991). In the family Theridiidae, they have been found to be an important part of prey wrapping silk, where they are held together by aciniform fibers (La Mattina et al. 2008). They are also present, together with other silk types, in orb web stabilimenta of Argiope Audouin, 1826 (Tillinghast et al. 1981).

Spiders of the family Nephilidae use minor ampullate fibers to construct the first, nonadhesive spiral of the orb web (Work 1981). This first spiral is necessary for constructing the second, sticky spiral, which is laid by walking on the first one. In the Nephilidae, both spirals stay in the web, but in other orbweaving Araneoidea, the spiders cut the first spiral out whilst completing the second (Work 1981). Spiders of the genus Cyrtophora Simon, 1864 (Araneidae) use only minor ampullate fibers for constructing the meshed-sheet-resembling orb web (Peters 1993). Finally, minor ampullate silk combined with aciniform fibrils is used for bridging lines in the Araneoidea (Peters 1990). Bridging lines are the airborne lines 
used by the spider for moving to distant places, once these threads have adhered to a substrate (Peters \& Kovoor 1991).

The quantities produced and the physical properties of materials produced by silk glands depend on the size and morphology of each gland. The glands are composed of two main parts, the secretory part and the spinning duct. The secretory part is usually composed of two secretory zones that differ in their transparency and/or colour. They produce different products: the distal zone produces the core and the proximal one produces the coat of the fiber (Kovoor 1987). The secretory part is usually tubular (called the tail), and, in those glands that are required to produce a large amount of silk very rapidly, there is also a wide globular ampulla just before the spinning duct, for storing the silk precursor prior to usage (Kovoor 1987). The spinning duct processes the material from a liquid solution to the solid fiber. In ampullate glands, it starts with a heavily sclerotised funnel, makes two switchbacks en route to the spinnerets to form a loop, and the three segments of the loop are all enveloped in a single sheath. The spider's silk glands open on the appendages at the posterior end of its abdomen (spinnerets) through hollow setae called spigots.

The glands that produce large amounts of silk dope usually have an elongated secretory part. However, in some spider groups, the secretory part is branched rather than being simple and elongated. Thus far, bifurcated tail sections of minor ampullate glands have been found in Amaurobius fenestralis (Stroem, 1768) (Apstein 1889: plate 5, Fig. 75) and A. ferox (Walckenaer, 1830) (Atanasiu-Dumitresco 1941: plate 2, Figs. $4,5)$. Irregularly branched tails of both the major and minor ampullate glands have also been found in some Agelenidae, such as Eratigena atrica (C.L. Koch, 1843) (Kiesow-Starck 1932: Figs. 6-8 under the name Tegenaria atrium; Kovoor 1976, 1987) and Agelena labyrinthica (Clerck, 1757) (Apstein 1889: Fig. 67; Kiesow-Starck 1932: Figs. 18, 20). The precise gland morphology in the latter remains uncertain, however, because other studies have found simple ampullate glands in this species (Kovoor 1976: Fig. 1). Misidentification of the studied material, or observation of only some of the ampullate glands, might explain this apparent anomaly. Morphological features of the spinning glands are not mentioned in other studies of similar species, such as Agelena limbata Thorell, 1897 (Park \& Moon 2002). Irregularly branched tails in ampullate glands have also been found in Tegenaria ferruginea (Panzer, 1804) although the results were erroneously presented under the name $T$. domestica (Clerck, 1757) in Johansson (1914) and Kiesow-Starck (1932: Fig. 11). Notwithstanding uncertainty regarding species identity, the morphology of the silk glands is certainly variable even within the family Agelenidae. For example, simple ampullate glands have been found in other agelenid species such as $T$. domestica (Johansson 1914: Fig. 5; Kiesow-Starck 1932: Figs. 12-14; both authors refer to this species under the name $T$. derhami Hansen, 1882; Atanasiu-Dumitresco 1941: Figs. 9-10).

The aim of this study is to compare the morphology of the minor ampullate glands in closely related cribellate and ecribellate groups of spiders, where the phylogenetic relationships indicate that the cribellate band has been lost more than once. These species come from within the Amaurobioidea, the monophyletic sister clade to the clade containing Dionycha

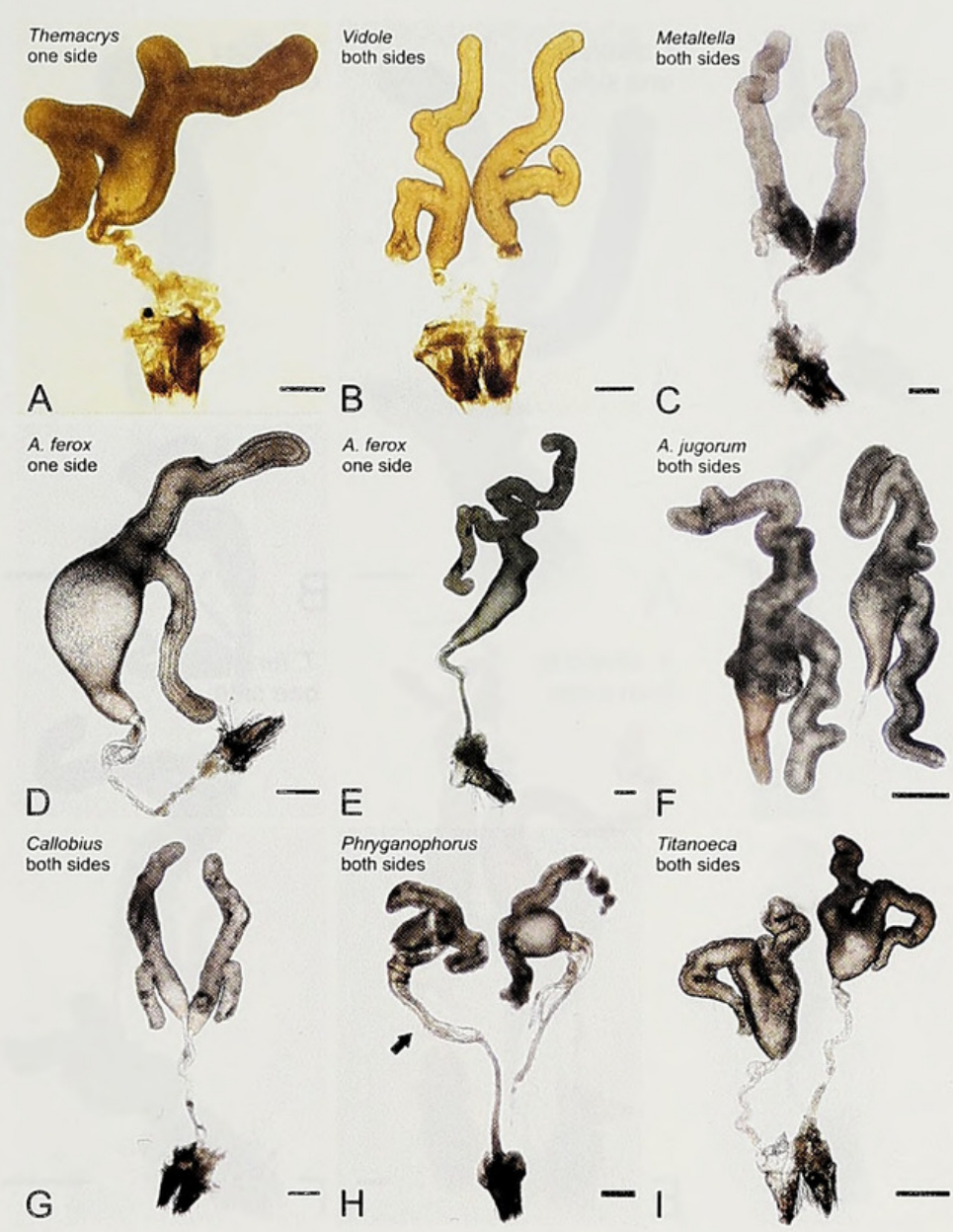

Figure 1.-Bifurcated minor ampullate glands of cribellate representatives of the superfamily Amaurobioidea. Either "one side" or "both sides" of the abdomen, split medially, are depicted. (A) Themacrys silvicola female, the side branch is approximately the same length as the axial one, additional branching is apparent. (B) Vidole sothoana female, the side branches are slightly shorter than the axial one, the side branch of the left gland is unusually turned to the front, additional branching is apparent. (C) Metaltella simoni female, the ampulla is completely missing, the proximal secretory zone is much darker than the distal one, the side branches are much smaller than the axial ones, the side branch of the right gland is not seen because it is behind the axial one. (D) Amaurobius ferox female, the ampulla and the constriction proximally from it are apparent, the side branch is approximately the same length as the axial one. (E) Amaurobius ferox male; in comparison with the conspecific female the storage ampulla is smaller, but besides that other reductions are not apparent. (F) Amaurobius jugorum female, constriction proximally from the ampulla is apparent, the side branch is approximately the same length as the axial one, additional branching is apparent. (G) Callobius bennetti female, the ampulla is completely missing, the side branches are shorter than the axial ones. (H) Phryganophorus candidus female, the ampulla and the constriction proximally from it are apparent, both branches are approximately the same length, they direct to the sides, the duct is relatively long, the loop covers a third of the distance between the funnel and the spinneret (marked by an arrow). (I) Titanoeca quadriguttata female, initially both branches direct to the front and then the side one turns backwards, the side one is longer than the axial one, additional branching is apparent. The scale bars represent $200 \mu \mathrm{m}$. 


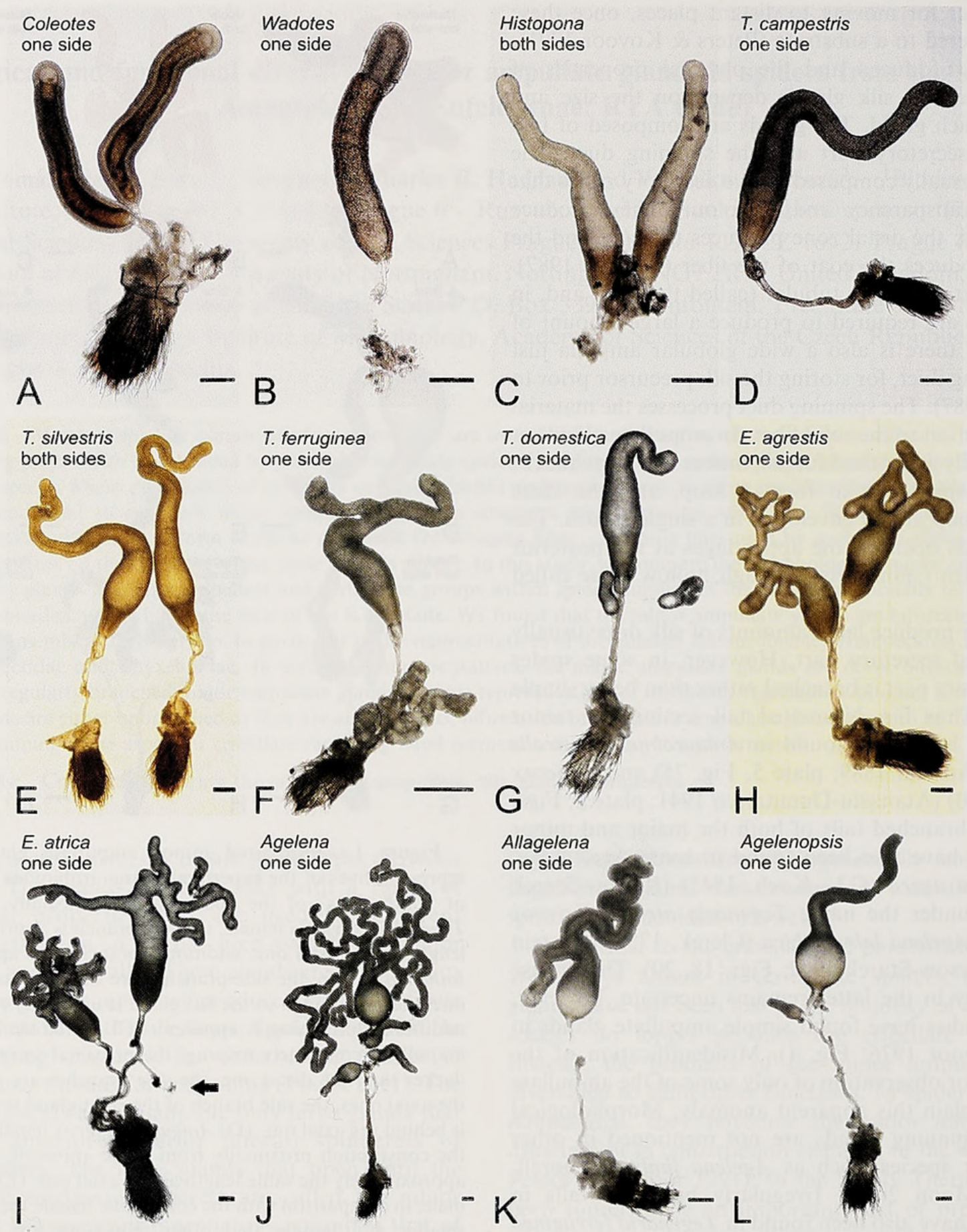

Figure 2.-Minor ampullate glands of representatives of Agelenidae spiders. Either "one side" or "both sides" of the abdomen, split medially, are depicted. (A) Coelotes terrestris female, two glands of almost the same size open on each posterior median spinneret, the ampulla is completely missing, the distal secretory zone is lighter and much shorter than the proximal one. (B) Wadotes calcaratus female, one gland from the couple was lost during dissection, the ampulla is completely absent, the distal secretory zone is shorter and lighter than the proximal one. (C) Histopona torpida female, the proximal secretory zone is darker than the distal one. (D) Tegenaria campestris male, apparent are the long distal secretory zone and the short proximal zone. (E) Tegenaria silvestris female, apparent is the constriction proximally from the ampulla, the proximal secretory zone is darker than the distal one, the secretory part is enlarged by elongation. (F) Tegenaria ferruginea juvenile female, the secretory part is enlarged by bifurcation. (G) Tegenaria domestica female. (H) Eratigena agrestis female, the secretory part is enlarged by irregular branching. (I) Eratigena atrica female, the secretory part is enlarged by irregular branching, the dwarf gland is marked by an arrow. (J) Agelena labyrinthica female; (K) Allagelena gracilens, female; (L) Agelenopsis pennsylvanica female. The scale bars represent $200 \mu \mathrm{m}$.

and Lycosoidea (see Fig. 5 in Miller et al. 2010, and Fig. 1 in Garrison et al. 2016). We also compare these glands with the major ampullate glands within each species. We identified a bifurcated secretory part of the minor ampullate glands in cribellate spiders from the families Amaurobiidae, Titanoecidae, Desidae, Amphinectidae and Phyxelididae. Furthermore, we found ramified (more than two branches) secretory parts of both major and minor ampullate glands in some Agelenidae, a 


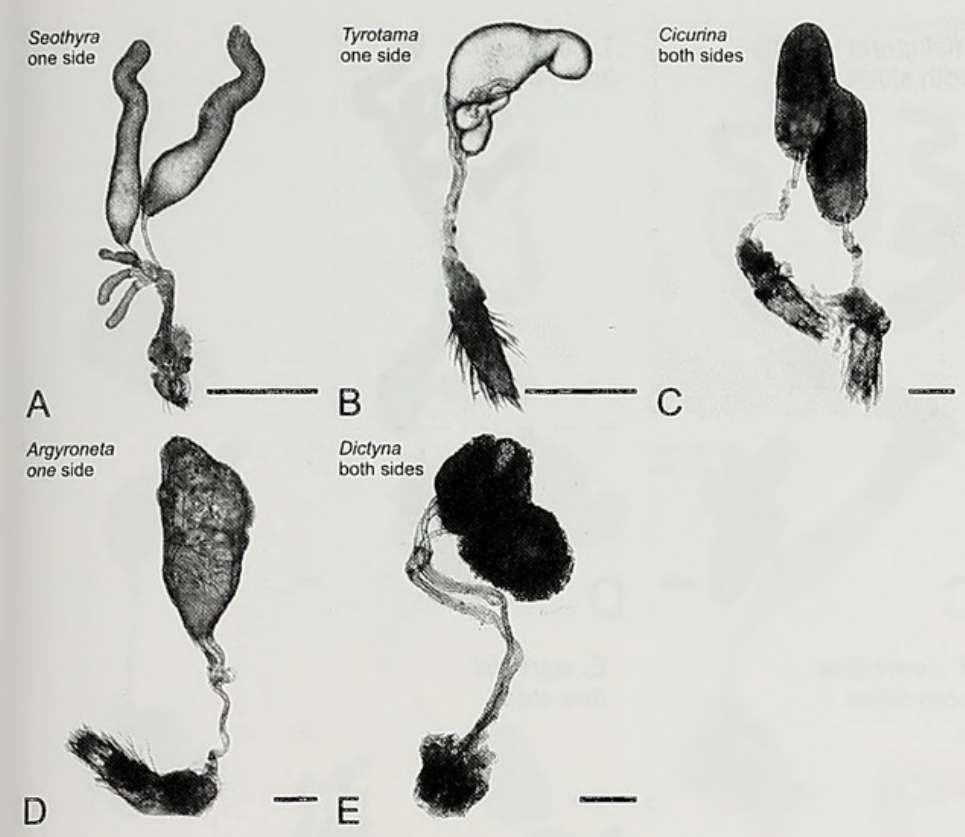

Figure 3.- Simple minor ampullate glands of the representatives of the superfamily Amaurobioidea and its outgroups. Either "one side" or "both sides" of the abdomen, split medially, are depicted. (A) Seothyra schreineri juvenile female, two functional and probably four (the fourth is not visible) accessory glands. (B) Tyrotama australis female, the ampulla and the two accessory glands are apparent. (C) Cicurina cicur female, the secretory part is not elongated (the tail is missing), the distal secretory zone is darker than the proximal one. (D) Argyroneta aquatica subadult male. (E) Dictyna uncinata female, the secretory part is not elongated (the tail is missing), the duct is relatively long, the loop covers one third of the distance between the funnel and the spinneret. The scale bars represent $200 \mu \mathrm{m}$.

spider group that no longer has a cribellum (Miller et al. 2010). In other Agelenidae, Dictynidae, and also the studied outgroups of Amaurobioidea, Hersiliidae and Eresidae, the minor ampullate glands are simple, i.e., without bifurcation. In the hahniid genera Antistea Simon, 1897 and Cybaeus L. Koch, 1868 and the studied representatives of Zodariidae, another outgroup of Amaurobioidea, the minor ampullate glands are absent. We use our data to discuss the functional significance of bifurcation of the minor ampullate glands in cribellate spiders.

\section{METHODS}

The material studied (Table 1) includes representatives of ten spider families that are at the base of the RTA clade, the majority of which are usually included in the superfamily Amaurobioidea. We also studied representatives of the families Eresidae and Hersiliidae as outgroups to the RTA clade.

The spinning glands of fresh spiders were dissected in embryo dishes using physiological solution $(0.9 \%$ aqueous solution of sodium chloride) and viewed under an Olympus SZX12 stereomicroscope. They were subsequently transferred in a drop of physiological solution onto a microscope glass slide with a small prefabricated circular impression and photographed under a Nikon Eclipse 80i light microscope. Voucher specimens are deposited in the Crop Research Institute, Prague (Czechia).

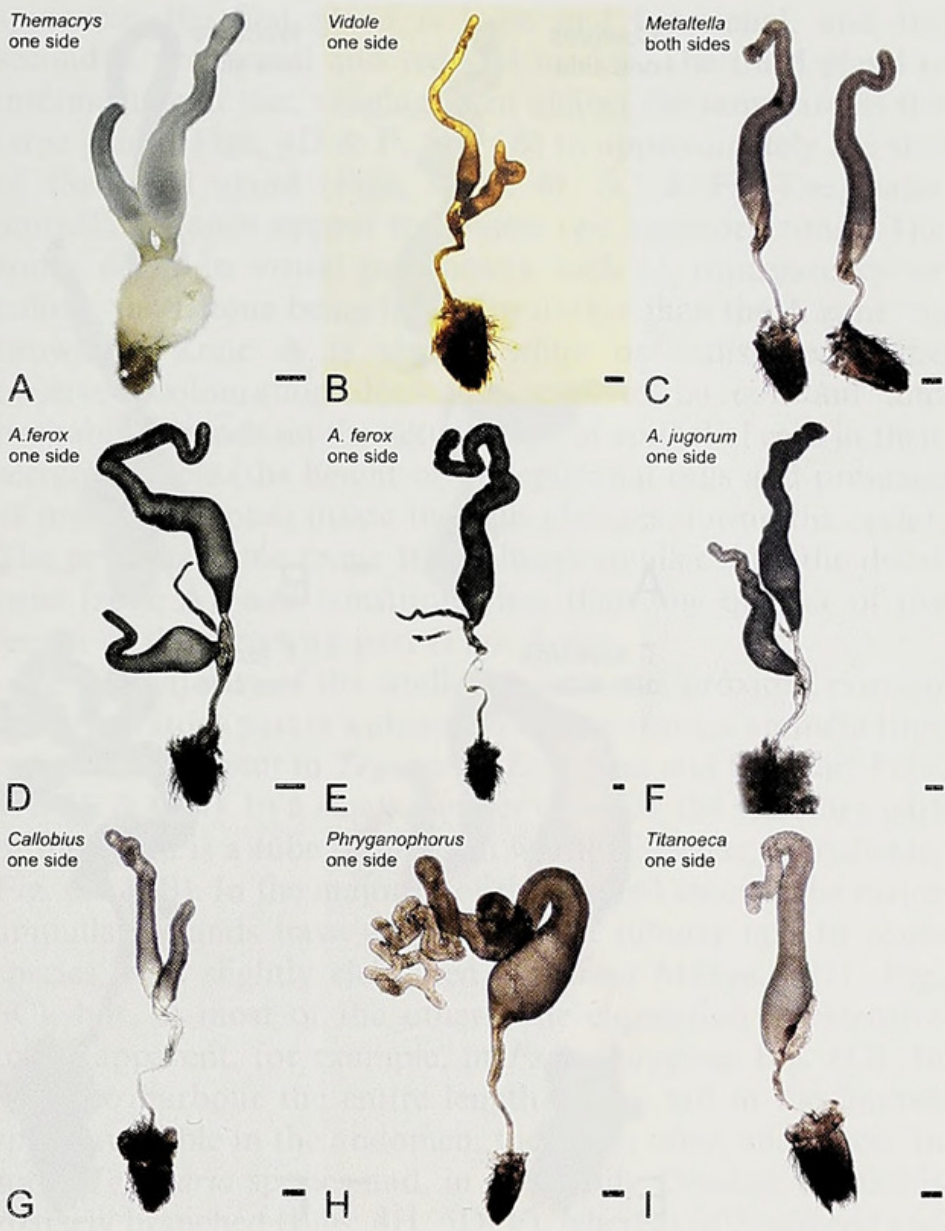

Figure 4.-Major ampullate glands of the cribellate representatives of the superfamily Amaurobioidea. Either "one side" or "both sides" of the abdomen, split medially, are depicted. (A) Themacrys silvicola female. (B) Vidole sothoana female. (C) Metaltella simoni female. (D) Amaurobius ferox female. (E) Amaurobius ferox male. (F) Amaurobius jugorum female. (G) Callobius bennetti female. (H) Phryganophorus candidus female, the secretory part is enlarged by irregular branching. (I) Titanoeca quadriguttata female. The scale bars represent $200 \mu \mathrm{m}$.

\section{RESULTS}

Minor ampullate glands. - We found no minor ampullate glands in Zodarion Walckenaer, 1847, Psammorygma Jocqué, 1991, Cybaeus, and the species from the Hahniidae. In the majority of studied species, only one pair of minor ampullate glands was present (Figs. 1, 3C-E). More pairs were observed in outgroup species (Eresidae, Hersiliidae; also in representatives of the clades Lycosoidea and Dionycha, which were not included in this study) and the Agelenidae. In the Agelenidae, there were either two pairs of glands of almost the same size (Agelenopsis Giebel, 1869, Fig. 2L; Coelotes Blackwall, 1841, Fig. 2A; Wadotes Chamberlin, 1925, Fig. 2B-here only one gland is shown; Eratigena Bolzern, Burckhardt \& Hänggi, 2013, Fig. 2H \& I), or one large and two smaller "dwarf pairs" (Histopona Thorell, 1869, Tegenaria Latreille, 1804, Fig. 2CG; Agelena Walckenaer, 1805, Allagelena Zhang, Zhu \& Song, 2006, Figs. 2J \& K). Dwarf glands can easily be lost during dissection and are thus not always apparent (e.g., Fig. 2). A system consisting of three pairs of co-occurring glands has previously been shown to allow production of fibers, even during proecdysis (Townley et al. 1993). 


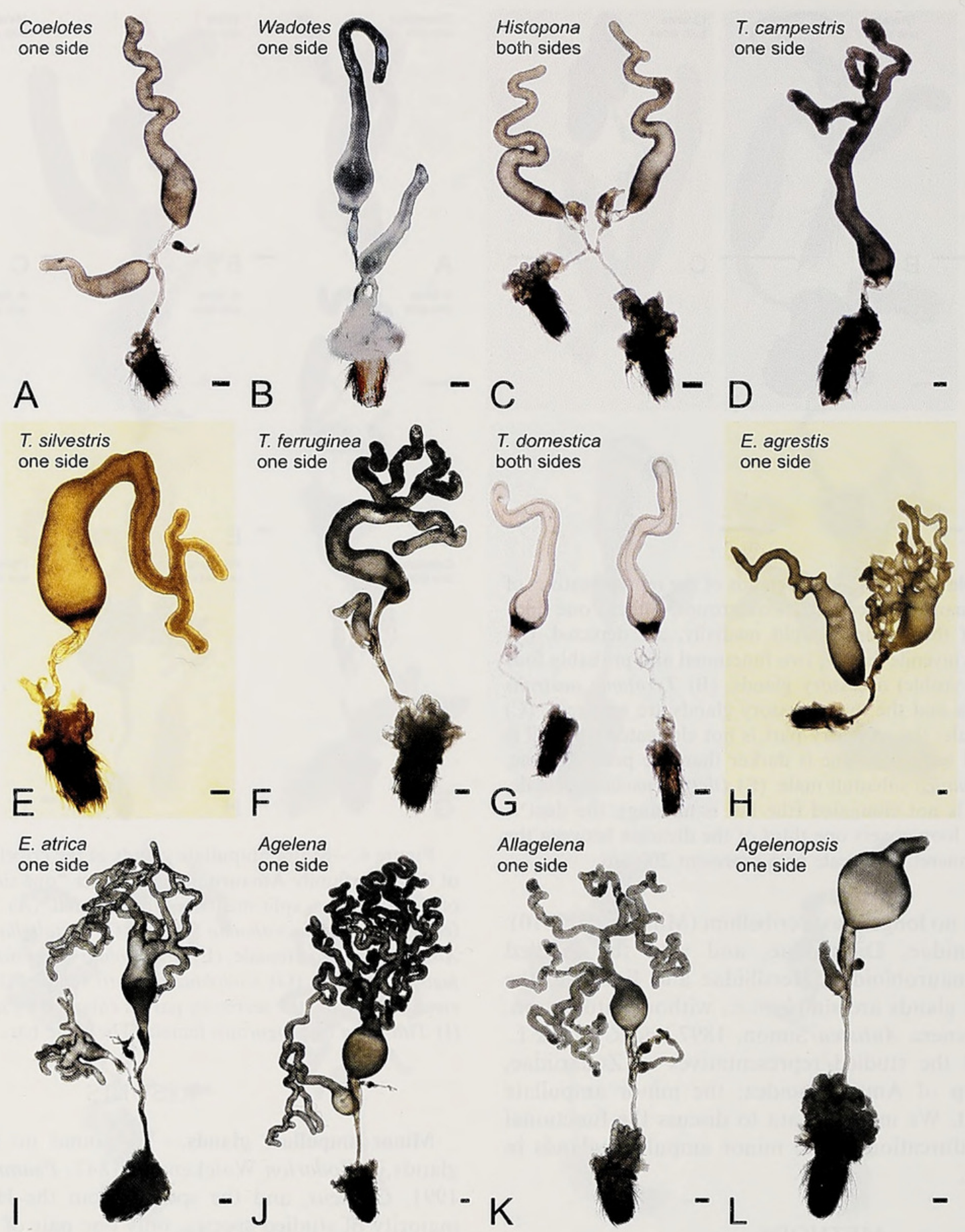

Figure 5.-Major ampullate glands of the representatives of Ageienidae spiders. Either "one side" or "both sides" of the abdomen, split medially, are depicted. (A) Coelotes terrestris female. (B) Wadotes calcaratus female. (C) Histopona torpida female. (D) Tegenaria campestris male. (E) Tegenaria silvestris female. (F) Tegenaria ferruginea juvenile female. (G) Tegenaria domestica female. (H) Eratigena agrestis female. (I) Eratigena atrica female. (J) Agelena labyrinthica female. (K) Allagelena gracilens female. (L) Agelenopsis pennsylvanica female, the distal (unbranched) part of the secretory zone is broken. In D-F and $\mathrm{H}-\mathrm{K}$, the secretory part is enlarged by irregular branching. The scale bars represent $200 \mu \mathrm{m}$.

The minor ampullate glands were found to possess two secretory zones in the studied species. The zones differed in visual parameters (transparency and colour). The proximal zone is usually smaller than the distal zone (e.g., Fig. 2D), although in representatives of the agelenid subfamily Coelotinae (Coelotes, Fig. 2A; Wadotes, Fig. 2B), it is significantly larger.

The proximal portion of the secretory part is in some cases widened to form a storage ampulla (e.g., Figs. 1D \& H, 2E \&
$\mathrm{H})$. The most proximal part of the ampulla is sometimes constricted (e.g., Figs. 1D \& F, 2E). In the majority of the studied species, the minor ampullate glands have an unbranched tubular tail (Figs. 2A-E, 3, Table 2), but in some species the tail is bifurcated (Fig. 1). One branch usually continues anteriorly in the axis of the gland (axial branch), whereas the second one grows to the side (side branch) and then it turns backwards, toward the spinneret (Fig. 1A-G \& I). The side branch is either shorter (Fig. 1B, C \& G) or of the 


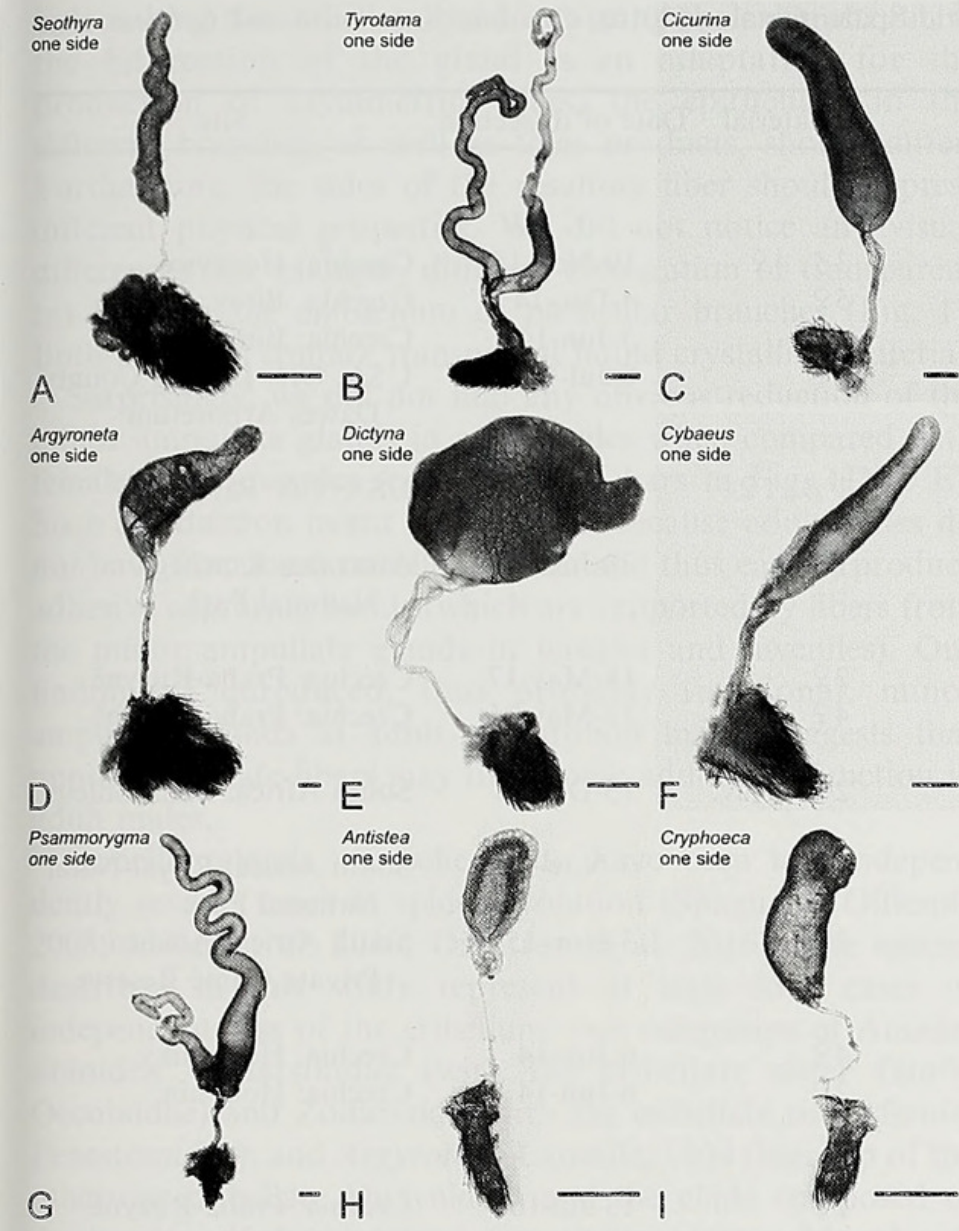

Figure 6.-Major ampullate glands of the representatives of the superfamily Amaurobioidea and its outgroups. Only "one side" of the abdomen, split medially, is depicted. (A) Seothyra schreineri juvenile female. (B) Tyrotama australis female. (C) Cicurina cicur female. (D) Argyroneta aquatica subadult male. (E) Dictyna arundinacea female. (F) Cybaeus angustiarum female. (G) Psammorygma sp., female. (H) Antistea elegans female. (I) Cryphoeca silvicola male. The scale bars represent $200 \mu \mathrm{m}$.

same length as the axial branch (Fig. 1D, F \& H). In a minority of cases, it is longer (Fig. 1I), and occasionally both branches protrude to the side (Fig. $1 \mathrm{H}$ ). In $T$. ferruginea the tail has 2-3 branches in juveniles (Fig. 2F) and 3-4 branches in adult females, while in Eratigena and the primary glands of Agelena (Fig. 2J) and Allagelena, it is multiply branched (Fig. $2 \mathrm{H}$, I \& K). In some Amaurobiidae, Phyxelididae and Titanoecidae, we found slight marks of additional branching (Fig. 1A, B, F \& I).

The spinning duct is usually relatively short and carries a short loop on its most distal part, close to the duct funnel, although in Dictynidae (Fig. 3E), Desidae (Fig. 1H) and some Amaurobiidae (Fig. 1D-G) the loop is longer, covering more than one third of the distance between the funnel and the spinneret.

Major ampullate glands. - In contrast to the minor ampullate glands, the major ampullate glands are present in all the studied species. In the majority of species, they are well developed, although there are exceptions; for instance in Seothyra Purcell, 1903 (Eresidae), they are relatively small and are hidden within the piriform glands (Fig. 6A). There are three major ampullate glands attached to one anterior lateral spinneret: the first gland is large and functional, and the second is very small and reduced in size. The third gland is intermediate in size, ranging from almost the same size as the large gland (Figs. 4D \& F, 5H, 6B) to approximately the size of the small gland (Figs. 4E \& 4I, 5C \& F). The major ampullate glands appear to possess two secretory zones. The zones differ in visual parameters such as transparency or colour, the B zone being lighter or darker than the A zone, or brownish. Zone A is always white or transparent. The observed colouration does not seem to be constant and probably depends on the actual stage of epithelial cells in their secretory cycle (the height of the epithelial cells and presence of product droplets inside the cells changes during the cycle). The proximal zone (zone B) is always smaller than the distal zone (zone A), and constitutes less than one quarter of the length of the secretory part (Figs. 4-6).

In the majority of the studied species, the proximal portion of the secretory part is widened to form a storage ampulla (this was most apparent in Tegenaria, Eratigena and Desidae; Figs. $4 \mathrm{H}, 5 \mathrm{E} \& \mathrm{G}-\mathrm{I})$. In a small number of cases, the secretory part of the gland is a tube of uniform width (Eresidae, Hersiliidae; Fig. 6A \& B). In the majority of the studied species, the major ampullate glands have an unbranched tubular tail. In some species, it is slightly elongated (Cicurina Menge, 1871, Fig. $6 \mathrm{C}$ ), but, in most of the others, the elongation is extensive (most apparent, for example, in Psammorygma; Fig. 6G). In order to harbour the entire length of the tail in the limited space available in the abdomen, the tail is often undulated. In some Tegenaria species and, in the family Desidae, the tail is sparsely branched (Figs. 4H, 5D-F), whereas in Eratigena and the primary glands of Agelena (Fig. 5J) and Allagelena, the tail is densely branched (Figs. 5H, I \& K). The spinning duct of the major ampullate gland is relatively short and carries a short loop on its most distal part, which lies close to the duct funnel.

\section{DISCUSSION}

We have shown that bifurcated minor ampullate glands are restricted almost exclusively to cribellate representatives of Amaurobioidea, sensu Garrison et al. (2016). The bifurcation might simply be a means through which more material can be produced, but the co-occurrence of cribellar glands with bifurcated minor ampullate glands suggests that bifurcation may be important for correct formation of the cribellate band structure.

A comparison between the morphology and function of the minor and major ampullate glands in cribellate and ecribellate Amaurobioidea spiders provides some insight. In the cribellate spiders that were studied, the products of the major and minor ampullate glands presumably serve different functions. The major ampullate fibers are used for draglines, ballooning or construction of webs. The minor ampullate glands presumably produce undulating fibers supporting cribellate fibrils in the adhesive bands for capturing prey (shown for Deinopidae and Eresidae - Peters 1992a, b).

The morphology of the major and minor ampullate glands in cribellate spiders was also found to differ - the major ampullate glands being simple (Fig. 4), in contrast to the bifurcated nature of their minor ampullate counterparts (Fig. 1). Bifurcation of the secretory part might produce a fiber that 
Table 1.- The spider material studied. Family classification follows World Spider Catalog (2016). Cicurina, Argyroneta and Cybaeus after Murphy \& Roberts (2015). Higher taxa after Miller et al. (2010).

Family/Species

Cribellum present

Amaurobiidae

Amaurobius fenestralis (Stroem, 1768)

Amaurobius ferox (Walckenaer, 1830)

Amaurobius jugorum L. Koch, 1868

Callobius bennetti (Blackwall, 1846)

Amphinectidae

Metaltella simoni (Keyserling, 1878)

Desidae

Phryganophorus candidus (L. Koch, 1872)

Dictynidae

Dictyna arundinacea (Linné, 1758)

Dictyna uncinata Thorell, 1856

Eresidae

Seothyra schreineri Purcell, 1903

Phyxelididae

Themacrys silvicola (Lawrence, 1938)

Vidole sothoana Griswold, 1990

Titanoecidae

Titanoeca quadriguttata (Hahn, 1833)

Titanoeca schineri L. Koch, 1872

Cribellum absent

Agelenidae

Agelena labyrinthica (Clerck, 1757)

Agelenopsis pennsylvanica (C.L. Koch, 1843)

Allagelena gracilens (C. L. Koch, 1841)

Coelotes terrestris (Wider, 1834)

Eratigena agrestis (Walckenaer, 1802)

Eratigena atrica (C. L. Koch, 1843)

Histopona torpida (C. L. Koch, 1837)

Tegenaria campestris C. L. Koch, 1834

Tegenaria domestica (Clerck, 1757)

Tegenaria ferruginea (Panzer, 1804)

Tegenaria silvestris L. Koch, 1872

Wadotes calcaratus (Keyserling, 1887)

Dictynidae

Argyroneta aquatica (Clerck, 1757)

Cicurinidae

Cicurina cicur (Fabricius, 1793)

Hahniidae

Antistea elegans (Blackwall, 1841)

Cryphoeca silvicola (C. L. Koch, 1834)

Cybaeus angustiarum L. Koch, 1868

Hersiliidae

Tyrotama australis (Simon, 1893)

Zodariidae

Psammorygma sp.

Zodarion germanicum (C. L. Koch, 1837)

RTA: Amaurobioidea

Material Date of dissection Site

\begin{tabular}{|c|c|}
\hline 30,49 & 19-Nov-15 \\
\hline 5 ㅇ & 4-Dec-14 \\
\hline 4 우 & 3-Jun-14 \\
\hline 29 & 6-Jul-14 \\
\hline
\end{tabular}

RTA: Amaurobioidea

RTA: Amaurobioidea

RTA: Amaurobioidea

$\begin{array}{ll}1 \%, 1 q & \text { 6-Jul-14 } \\ 1 \% & \text { 28-Jul-14 }\end{array}$

\section{Outgroup of RTA}

RTA: Amaurobioidea

2 우

4 요

$2 q, 2$ juv.

2 우

29

RTA: Amaurobioidea

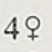

2 우

RTA: Amaurobioidea

\author{
Czechia: Hostivice \\ Czechia: Bítov \\ Czechia: Bítov \\ USA: OH: Licking County, \\ Dawes Arboretum
}

USA: CA: Riverside

Australia: Kinchega National Park

18-May-17

19-May-15

15-Dec-15

3-Nov-15

3-Nov-15

6-Jun-14

6-Jun-14

Czechia: Praha-Ruzyně

Czechia: Praha-Ruzyně

South Africa: Bankfontein

South Africa: Royal Natal National Park

South Africa: Amanzi Private Game Reserve

Czechia: Havraníky

Czechia: Hodonín

19-Nov-14

\begin{tabular}{|c|c|c|}
\hline $10,5 q$ & 5-Nov-14 & Czechia: Doksy \\
\hline $4 q$ & 21-May-15 & Czechia: Praha-Ruzyně \\
\hline $7 q$ & 4-Oct-16 & Czechia: Staré Splavy \\
\hline 10 & 4-Oct-16 & Czechia: Pec pod Sněžkou \\
\hline $5 q$ & 19-Sep-15 & Czechia: Pec pod Sněžkou \\
\hline 29,1 juv. & 15-Dec-15 & South Africa: Bankfontein \\
\hline $20^{\circ}, 2$ ㅇ & 13-Jan-16 & $\begin{array}{l}\text { South Africa: Ndumo } \\
\text { Game Reserve }\end{array}$ \\
\hline 1 & 21-May-15 & Czechia: Praha-Liboc \\
\hline
\end{tabular}

13-Jul-16

10-Sep-09

12-Jul-16

18-Nov-14

5-Jun-14

18-Nov-14

18-Nov-14

6-Jun-14

7-Dec-15

4-Nov-15

13-Jul-14

RTA: Amaurobioidea

RTA: Amaurobioidea

RTA: Amaurobioidea

Czechia: Praha-Ruzyně

USA: OH: Akron

Czechia: Valtice

Czechia: Podmolí

Czechia: Lukov

Czechia: Hostivice

Czechia: Lukov

Czechia: Lukov

Czechia: Znojmo

Czechia: Praha-Ruzyně

Slovenia: Orehek,

Žegnana jama

USA: OH: Licking County, Dawes Arboretum

Outgroup of RTA

RTA: outgroup of Amaurobioidea

\section{Game Reserve
Czechia: Praha-Liboc}

is asymmetric in its cross-section, with one side containing more product from the adjacent branch of the secretory part. The asymmetry of the fiber could enhance its undulating properties and/or could secure different adhesion forces on its different sides. The latter seems unlikely, since presumably the products of both branches are ensheathed by the product of the proximal portion of the secretory epithelium. Alternatively, the undulating of these fibers could also be caused simply 
by combing the cribellate band out using the calamistrum. If the bifurcation of the gland is an adaptation for the production of asymmetric fibers, the epithelium in the different branches, as well as their products, should differ. Furthermore, the sides of the resulting fiber should express different physical properties. We did not notice any visual differences (for example, different colouration or transparency) between the epithelium of particular branches (Fig. 1). Both branches contain transparent liquid crystalline material.

Surprisingly, we did not find any obvious reduction of the minor ampullate glands in adult males when compared with females and juveniles (compare scale bars in Fig. 1D \& E). Such a reduction might be expected, because adult males do not have functional cribellar glands, and thus cannot produce adhesive capturing bands (which are supported by fibers from the minor ampullate glands in females and juveniles). Our finding of unreduced, thus probably functional, minor ampullate glands in adult amaurobiid males suggests that minor ampullate fibers may fulfil some additional function in adult males.

Cribellar glands are believed to have been lost independently several times in spider evolution (Spagna \& Gillespie 2008; Miller et al. 2010; Dimitrov et al. 2016). The species described in this study represent at least four cases of independent loss of the cribellum: two outgroups of Amaurobioidea - Hersiliidae (with the cribellate sister family Oecobiidae) and Zodariidae (with the cribellate sister family Penestomidae), and Argyroneta Latreille, 1804 (ingroup of the otherwise cribellate Dictynidae) and the clade composed of Agelenidae, Hahniidae and Cicurinidae (sensu Murphy \& Roberts 2015 , with the cribellate sister family Dictynidae). In addition to the cribellar glands, the paracribellar glands and frequently also the pseudoflagelliform glands have been lost. In contrast, minor ampullate glands often remain in taxa that have lost their cribellum (see, for example, Griswold et al. 2005; Murphy \& Roberts 2015). We studied representatives of two groups that have lost the minor ampullate glands independently, in particular Hahniidae (Antistea, Cybaeus) and some Zodariidae (Zodarion, Psammorygma). However, the spigots of the minor ampullate glands have been observed in some other Zodariidae (Ramirez 2014).

In contrast to cribellate spiders, in the ecribellate spiders and Dictyna Sundevall, 1833 that are studied here the products of the major and minor ampullate glands presumably serve the same respective functions, i.e., minor ampullate fibers are mainly used for reinforcing the major ampullate fibers in draglines or in construction elements of the webs, such as in species studied by Work (1981) and Peters and Kovoor (1991). Dictyna produces cribellate capturing bands but they do not contain undulating fibers (Eberhard \& Pereira 1993). Such undulating fibers are, however, found in some other dictynids, for example the genus Mallos O.P-Cambridge, 1902 (Griswold et al. 2005). It is thus not surprising that the morphology of these two gland types is almost identical in these spiders. In the family Agelenidae, this similarity also includes the presence of the system of three pairs of glands (i.e., three pairs of minor ampullate and three pairs of major ampullate glands), which, according to the findings of Townley et al. (1993) in Araneus Clerck, 175\%, suggests that each of them function in different instars or at different times during the molt cycle (Townley et al. 1993). The two accessory pairs produce fibers during alternate proecdyses (i.e., one pair producing fibers in oddnumbered stadia, the other pair producing fibers in evennumbered stadia).

The presence of non-functional pairs of glands is also manifested in spinneret morphology. There could be a tartipore - a scar on new cuticle after the collared opening that allows the ducts of the functional secondary ampullate gland to remain attached to the spigot on the old exoskeleton during proecdysis (Townley et al. 1993). The spigot of the last open secondary gland is replaced by a so-called nubbin in adults, i.e., the stage where the secondary ampullate glands are not necessary any more (Townley et al. 1993). Moulting spiders do not capture prey, thus the absence of this system in the studied cribellate spiders, where the minor ampullate glands play a role in production of adhesive capturing bands, is not surprising. In contrast, in the Agelenidae the minor ampullate glands presumably play the same role as the major ampullate glands - their products might participate in draglines and shelters that are produced even during proecdysis.

Spiders of the family Agelenidae build relatively large horizontal sheet webs instead of producing cribellate bands in order to capture their prey. For such webs, they need a large amount of silk. Therefore, it might have been advantageous for them to retain minor ampullate glands that have greater numbers of branches (Fig. 2F), thereby creating a larger surface area of secretory epithelium than the simple gland structures. Some species producing remarkably large webs, for example the genus Eratigena, and primary glands of Agelena and Allagelena, appear to have further enlarged the secretory epithelium surface area through increasing the number of branches (Fig. 2H, J \& K). These branches probably produce the same product (potentially in contrast to cribellate relatives).

In the other representatives of this family, branching is absent. In the species with simple glands that construct large webs (for example, some species of Tegenaria, and the genera Agelenopsis and Histopona), the secretory epithelium is enlarged by elongation (Fig. 2C-E).

Multiple branching of the secretory part of the minor and also the major ampullate glands in some Agelenidae is a unique feature among spider silk glands. Evolution of elongation instead of branching of the secretory part could have been driven by more advantageous rheology inside the simple glands. In order to decrease the energetic demands of spinning, spiders spin the fibers from the protein solution behaving as a liquid crystal (Knight \& Vollrath 1999). The initially randomly oriented proteins aggregate end-to-end into rod-shaped units. Due to a very high concentration of the solution (up to $50 \%$ of proteins, Tillinghast et al. 1984), these rods interact by non-covalent forces. As a resuit, they orient themselves parallel to one another (Viney et al. 1994; Viney 1997). This phase flows as a liquid but maintains some molecular orientation of the crystal (Vollrath \& Knight 2001). In branched glands, formation of the liquid crystal might be more complicated. From particular branches, the differently oriented protein molecules flow together. In contrast, in simple glands the formation of the liquid crystal is not disturbed by flows from different directions, and thus it is probably faster 


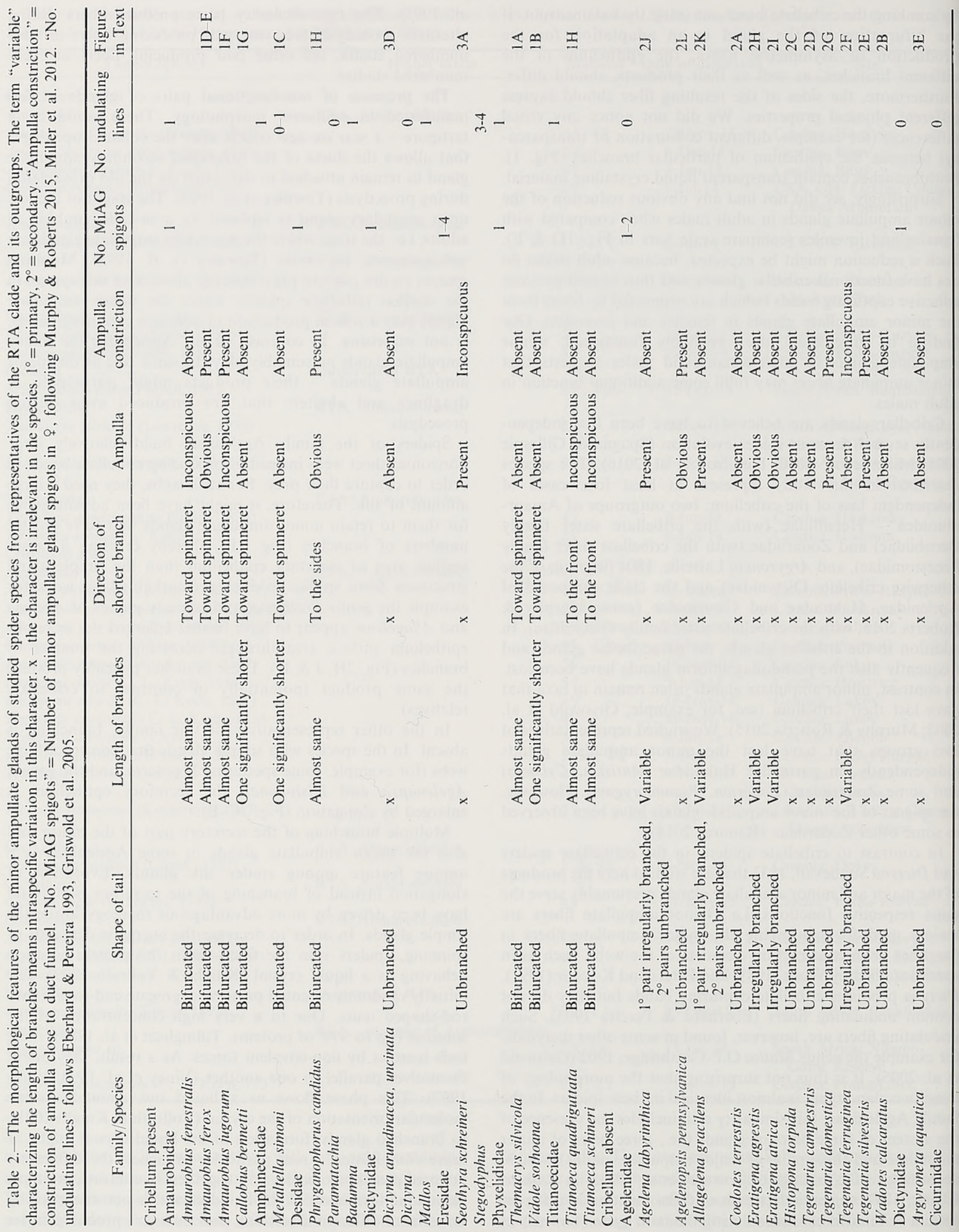




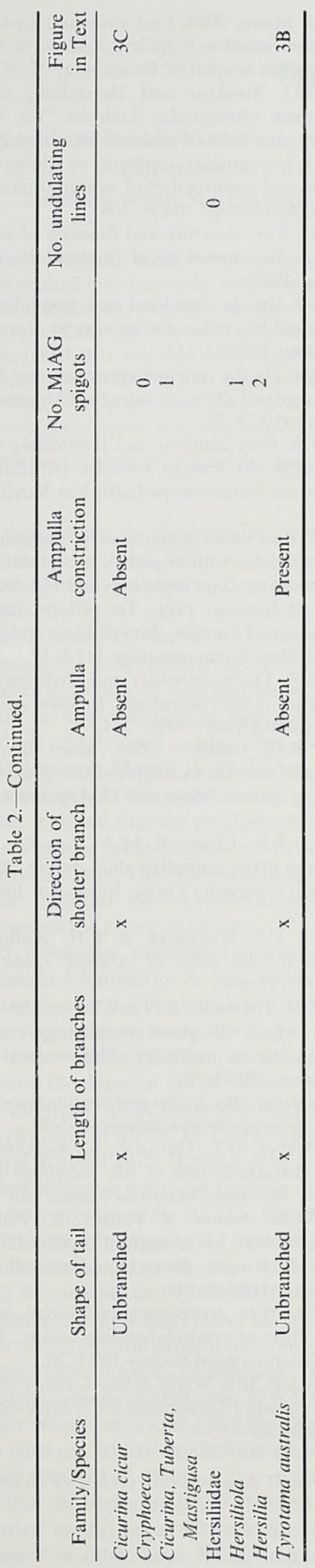

and more accurate. Therefore, in simple glands the spinning is perhaps energetically less demanding.

The species from the agelenid subfamily Coelotinae have only very small funnel webs. They possess relatively small minor ampullate glands that significantly differ from the minor ampullate glands of other studied species by very short distal and very long proximal secretory zone (Fig. 2A \& B). Such glands probably produce fibers with a thin core and a thick outer coat. The ratio between the size of the proximal and the distal secretory zone resembles that of piriform glands that produce fibers covered by glue (Kovoor 1987). It is possible that the minor ampullate glands in the Coelotinae also produce adhesive fibers functionally substituting for cribellate capturing bands.

The mentioned conclusions are based only on our knowledge about the studied group of RTA spiders (Amaurobioidea in broad sense). Outside this group, the morphological and functional features of the minor ampullate glands are different. For example, cribellate members of the Eresidae from the very base of araneomorph spiders also possess undulating fibers in the adhesive capturing bands, but the minor ampullate glands are simple (Fig. 3A). Simple minor ampullate glands are also observed in other cribellate, uloborid spiders (Kovoor 1977; Kovoor \& Peters 1988), which are known for their orb webs with a cribellate spiral instead of a spiral with viscous glue. However, in these cases their cribellate bands do not contain undulating fibers (Eberhard \& Pereira 1993), and instead minor ampullate fibers are used, together with the major ampullate fibers, for frames of their orb webs (Peters 1983, 1984).

The phylogenetic relationships among the families at the base of the RTA clade are still very unclear. The difficulties with uncovering relationships of particular groups of this clade are caused by the conflict among characters (homoplasy) and the lack of informative synapomorphies. Many characters from spigot morphology, related to silk glands, have been already extensively used in phylogenetic analyses (for example, Griswold et al. 2005). However, internal silk gland morphology provides many more characters that might be informative for future phylogenetic analyses.

\section{ACKNOWLEDGMENTS}

We thank Rick Vetter for Metaltella simoni and Stano Pekár for Phryganophorus candidus, Richard A. Bradley for determining Callobius bennetti and Wadotes calcaratus, and Mark Townley and Martín Ramírez for valuable comments on the manuscript. Milan Rezáč was supported by the Czech Ministry of Education, Youth and Sports and the Czech Ministry of Agriculture (projects LH13042 and MZe RO0415). Tomáš Krejčí was supported by Internal Grant Agency of the Faculty of Environmental Sciences, CULS Prague (project 4211013123133); Sara L. Goodacre was supported by Royal Society International Exchange Scheme grant IE141413, Veronika Řezáčová was supported by the long-term development program RVO61388971; Charles Haddad was supported by a National Research Foundation of South Africa (NRF) grant in the Competitive Funding for Rated Researchers programme (grant 95569). 


\section{LITERATURE CITED}

Apstein, C. 1889. Bau und Function der Spinndrüsen der Araneida. Archiv für Naturgeschichte 1889:29-74.

Atanasiu-Dumitresco, M. 1941. Contributions a l'etude anatomique et cytologique de l'appareil sericigene des araignees. Analele Academiei Romane (Bucuresti) Memoriile Sectiunii Stiintifice, Seria 3 16:773-840.

Dimitrov, D., L.R. Benavides, M.A. Arnedo, G. Giribet, C.E. Griswold, N. Scharff et al. 2016. Rounding up the usual suspects: a standard target-gene approach for resolving the interfamilial phylogenetic relationships of ecribellate orb-weaving spiders with a new family-rank classification (Araneae, Araneoidea). Cladistics doi: $10.1111 /$ cla. 12165

Eberhard, W.G. \& F. Pereira. 1993. Uitrastructure of cribellate silk of nine species in eight families and possible taxonomic implications (Araneae: Amaurobiidae, Deinopidae, Desidae, Dictynidae, Filistatidae, Hypochilidae, Stiphidiidae, Tengellidae). Journal of Arachnology 21:161-174.

Foelix, R.F. 2011. Biology of Spiders. 3rd ed. Oxford University Press, New York.

Garrison, N.L., J. Rodriguez, I. Agnarsson, J.A. Coddington, C.E. Griswold, C.A. Hamilton et al. 2016. Spider phylogenomics: untangling the Spider Tree of Life. PeerJ 4:e1719

Griswold, C.E., M.J. Ramírez, J.A. Coddington \& N.I. Platnick. 2005. Atlas of phylogenetic data for entelegyne spiders (Araneae: Araneomorphae: Entelegynae) with comments on their phylogeny. Proceedings of the California Academy of Sciences 56:1-324.

Johansson, B. 1914. Zur Kenntnis der Spinndruesen der Araneina. Acta Universitatis Lundensis, Nova Series 10(5):1-12.

Kiesow-Starck, I. 1932. Leistung und Bau des Spinnapparates einiger einheimischer Trichterspinnen. Jenaische Zeitschrift für Naturwissenschaft $66(1): 1-40$.

Knight, D.P. \& F. Vollrath. 1999. Liquid crystals and flow elongation in a spider's silk production line. Proceedings of the Royal Society B: Biological Sciences 266:519-523.

Kovoor, J. 1976. Caracteres adaptatifs et caracteres familiaux des glandes sericigenes dans le genre Hippasa E. Simon (Araneae, Lycosidae). Comptes Rendus de Troisième Réunion de Arachnologistes d'Expression Française, Les Eyzies 83-96.

Kovoor, J. 1977. L'appareil séricigène dans le genre Uloborus Latr. (Araneae, Uloboridae). I. Anatomie. Revue Arachnologique 1:89 102.

Kovoor, J. 1987. Comparative structure and histochemistry of silkproducing organs in Arachnids. Pp. 159-186. In Ecophysiology of Spiders. (W. Nentwig, ed.). Springer-Verlag, Berlin.

Kovoor, J. \& H.M. Peters. 1988. The spinning apparatus of Polenecia producta (Araneae, Uloboridae): structure and histochemistry. Zoomorphology 108:47-59.

La Mattina, C., R. Reza, X. Hu, A.M. Falick, K. Vasanthavada, S. McNary, et al. 2008. Spider minor ampullate silk proteins are constituents of prey wrapping silk in the cob weaver Latrodectus hesperus. Biochemistry 47:4692 4700 .

Miller, J.A., A. Carmichael, M.J. Ramírez, J.C. Spagna, C.R. Haddad, M. Rezáč, et al. 2010. Phylogeny of entelegyne spiders: affinities of the family Penestomidae (new rank), generic phylogeny of Eresidae, and asymmetric rates of change in spinning organ evolution (Araneae, Araneoidea, Entelegynae). Molecular Phylogenetics and Evolution 55:786-804.

Miller, J.A., C. Griswold, N. Scharff, M. Řezáč, T. Szuts \& M. Marhabaie. 2012. The velvet spiders: an atlas of the Eresidae (Arachnida, Araneae). ZooKeys 194:1-144.

Murphy J.A. \& M.J. Roberts. 2015. Spider Families of the World and Their Spinnerets. British Arachnological Society, York.
Park, J.G. \& M.J. Moon. 2002. Fine structural analysis of the silk apparatus in the funnel-web spider, Agelena limbata (Araneae: Agelenidae). Korean Journal of Entomology 32:223-232.

Peters, H.M. 1983. Struktur und Herstellung der Fangfäden cribellater Spinnen (Arachnida: Araneae). Ver Verhandlungen des Naturwissenschaftlichen Vereins in Hamburg 26:241-253.

Peters, H.M. 1984. The spinning apparatus of Uloboridae in relation to the structure and construction of capture threads (Arachnida, Araneida). Zoomorphology 104:96-104.

Peters, H.M. 1987. Fine structure and function of capture threads. Pp. 187-202. In Ecophysiology of Spiders. (W. Nentwig, ed.) Springer-Verlag, Berlin.

Peters, H.M. 1990. On the structural and glandular origin of the bridging lines used by spiders for moving to distant places. Acta Zoologica Fennica 190:309-314.

Peters, H.M. 1992a. On the spinning apparatus and the structure of the capture threads of Deinopis subrufus (Araneae, Deinopidae). Zoomorphology 112:27-37.

Peters, H.M. 1992b. Über Struktur und Herstellung von Fangfäden cribellater Spinnen der Familie Eresidae (Arachnida, Araneae). Verhandlungen des Naturwissenschaftlichen Vereins in Hamburg 33:213-227.

Peters, H.M. 1993. Functional organization of the spinning apparatus of Cyrtophora citricola with regard to the evolution of the web (Araneae, Araneidae). Zoomorphology 113:153-163.

Peters, H.M. \& J. Kovoor. 1991. The silk-producing system of Linyphia triangularis (Araneae, Linyphiidae) and some comparisons with Araneidae. Zoomorphology 111:1-17.

Ramírez, M.J. 2014. The morphology and phylogeny of dionychan spiders (Araneae: Araneomorphae). Bulletin of the American Museum of Natural History 390:1-374.

Spagna, J.C. \& R.G. Gillespie. 2008. More data, fewer shifts: Molecular insights into the evolution of the spinning apparatus in non-orb-weaving spiders. Molecular Phylogenetics and Evolution 46:347-368.

Tillinghast, E.K., S.F. Chase \& M.A. Townley. 1984. Water extraction by the major ampullate duct during silk formation in the spider, Argiope aurantia Lucas. Journal of Insect Physiology 30:591-596.

Tillinghast, E.K., E.J. Kavanagh \& P.H. Kolbjornsen. 1981 Carbohydrates in the webs of Argiope spiders. Journal of Morphology 169:141-148.

Townley, M.A., E.K. Tillinghast \& N.A. Cherim. 1993. Moult-related changes in ampuliate silk gland morphology and usage in the araneid spider Araneus cavaticus. Philosophical Transactions: Biological Sciences 340:25-38.

Viney, C. 1997. Natural silks: archetypal supramolecular assembly of polymer fibres. Supramolecular Science 4:75-81.

Viney, C., A.E. Huber, D.L. Duvaway, K. Kerkam \& S.T. Case. 1994. Optical characterization of silk secretions and fibers. Pp 120-136. In Silk Polymers: Materials Science and Biotechnology. (D. Kaplan, W.W. Adams, B. Farmer, C. Viney, eds). ACS Symposium Series, Vol. 544, American Chemical Society.

Vollrath, F. \& D.P. Knight. 2001. Liquid crystalline spinning of spider silk. Nature 410:541-548.

Work, R.W. 1981. Web components associated with the major ampullate silk fibers of orb-web-building spiders. Transactions of the American Microscopical Society 100:1-20.

World Spider Catalog 2016. World Spider Catalog. Natural History Museum Bern, version 17.5, accessed on 19 September 2016. online at http://wsc.nmbe.ch

Manuscript received 31 January 2016, revised 14 October 2016. 


\section{$2 \mathrm{BHL}$ Biodiversity Heritage Library}

Řezáč, Milan et al. 2017. "Morphological and functional diversity of minor ampullate glands in spiders from the superfamily Amaurobioidea (Entelegynae: RTA clade)." The Journal of arachnology 45(2), 198-208. https://doi.org/10.1636/joa-16-010-rezak.1.

View This Item Online: https://www.biodiversitylibrary.org/item/274742

DOI: https://doi.org/10.1636/joa-16-010-rezak.1

Permalink: https://www.biodiversitylibrary.org/partpdf/289902

\section{Holding Institution}

Smithsonian Libraries

\section{Sponsored by}

Biodiversity Heritage Library

\section{Copyright \& Reuse}

Copyright Status: In Copyright. Digitized with the permission of the rights holder

Rights Holder: American Arachnological Society

License: https://creativecommons.org/licenses/by-nc-sa/4.0/

Rights: http://www.biodiversitylibrary.org/permissions/

This document was created from content at the Biodiversity Heritage Library, the world's largest open access digital library for biodiversity literature and archives. Visit BHL at https://www.biodiversitylibrary.org. 